\title{
Taxane-cisplatin-fluorouracil as induction chemotherapy for advanced head and neck cancer: a meta-analysis of the 5-year efficacy and safety
}

Xu Qian ${ }^{1,2+}$, Chenming Ma ${ }^{1 \dagger}$, Thomas K Hoffmann ${ }^{3}$, Andreas M Kaufmann ${ }^{4}$ and Andreas E Albers ${ }^{1 *}$

\begin{abstract}
Background: The objective of this study was to compare the efficacy and safety of taxane (docetaxel or paclitaxel), cisplatin, and fluorouracil (Tax-PF) with cisplatin plus fluorouracil (PF) regimen by a meta-analysis of data retrieved from the literature.

Methods: Seven randomized clinical trials were identified, which included patients with advanced head and neck cancer who underwent induction chemotherapy with either a Tax-PF or PF protocol. The outcomes included the 3-year and 5-year overall survival (OS) and progression-free survival (PFS), overall response rate (ORR) and different types of adverse events.

Results: The 3-year OS rate (HR: 1.14; $95 \%$ Cl: 1.03 to $1.25 ; P=0.008$ ), 3-year PFS rate (HR: 1.24; 95\% Cl: 1.08 to 1.43; $P=0.002$ ), 5 -year OS rate (HR: $1.30 ; 95 \% \mathrm{Cl}, 1.09$ to $1.55 ; P=0.003)$, 5 -year PFS rate (HR: $1.39 ; 95 \% \mathrm{Cl}, 1.14$ to 1.70 ; $P=0.001)$ and ORR to chemotherapy (OR 1.66; $95 \% \mathrm{Cl}, 1.35$ to $2.05 ; P<0.001)$ of the patients in the Tax-PF group were statistically superior to those in the PF group. In terms of toxicities, the incidence of febrile neutropenia (OR 2.36; 95\% Cl, 1.62 to 3.46; $P<0.001$ ), alopecia (OR 8.22; 95\% Cl, 3.99 to 16.92; $P<0.001$ ), diarrhea (OR 1.57; 95\% $\mathrm{Cl}, 1.05$ to $2.36 ; P=0.03$ ) and leukopenia (OR 2.79; $95 \% \mathrm{Cl}, 1.86$ to $4.21 ; P<0.001$ ) was higher in the Tax-PF group.

Conclusion: The Tax-PF induction chemotherapy improved PFS and OS, and the ORR was better as compared to PF-based therapy regimens at the cost of a higher incidence of adverse events.
\end{abstract}

Keywords: Head and neck carcinoma; Induction chemotherapy; Docetaxel; Cisplatin; Fluoruracil; Survival

\section{Introduction}

Head and neck squamous cell carcinoma is one of commonest malignant tumors, frequently diagnosed in an unresectable advanced stage (Siegel et al. 2014). A meta-analysis on chemotherapy in head and neck cancer (MACH-NC) has demonstrated that concomitant chemoradio-therapy using traditional cisplatin and fluorouracil (PF) regimen improved the survival in patients with distant metastases and should be regarded as the principal treatment (Pignon et al. 2009). Nevertheless,

\footnotetext{
*Correspondence: andreas.albers@charite.de

${ }^{\dagger}$ Equal contributors

'Department of Otolaryngology, Head and Neck Surgery,

Charité-Universitätsmedizin Berlin, Campus Benjamin Franklin,

Hindenburgdamm 30, 12200 Berlin, Germany

Full list of author information is available at the end of the article
}

investigators are continuously evaluating new regimens in the induction setting to improve ORR, PFS and OS. Among agents introduced in the 1990s, taxanes have shown great promise for the treatment of head and neck squamous cell carcinoma (HNSCC) (Schrijvers and Vermorken 2000). The clinical efficacy of induction chemotherapy using a PF regimen doubled while a three-drug combination of taxane (docetaxel or paclitaxel), cisplatin, and fluorouracil (Tax-PF) is still undergoing evaluation in several randomized controlled trials (RCTs) with varying results (Blanchard et al. 2013; Forastiere et al. 2013; Tural and Kilickap 2014).

This meta-analysis was conducted to review all eligible RCTs comparing combined therapy with or without taxanes, with the aim of investigating whether Tax-PF 
therapy is more efficient than PF therapy for advanced head and neck cancer while adverse effects are still tolerable.

\section{Materials and methods}

Literature search

PubMed, Embase, SpringerLink, MEDLINE, the Cochrane Library and the American Society of Clinical Oncology (ASCO) Annual Meeting and ASCO virtual meeting databases were searched for entries until June 2014, using the following search keywords: "randomized", "head and neck cancer", "HNSCC", "induction chemotherapy" and "taxanes or docetaxel or paclitaxel". Articles and general reviews of this topic were examined and excluded manually.

\section{Study selection}

Clinical trials that fulfilled the following criteria were included in the study: (1) prospective RCT; (2) original articles that include a censored number of patients or Kaplan-Meier-curves; (3) studies that analyzed combined therapy regimen with taxanes versus without taxanes; (4) comparisons of combined Tax-PF induction chemotherapy to regimen with traditional PF double-chemotherapy (Figure 1).

To limit publication bias, only published data were included. Studies containing one of the following criteria (1) phase I clinical trial; (2) retrospective trial; (3) any review, comment, and case report were excluded from the analysis.

\section{Data extraction and study quality}

Studies were extracted from the databases by two of the authors separately. Next, between the authors a consensus was achieved that the data from the chosen publications met the inclusion criteria. Then the following information

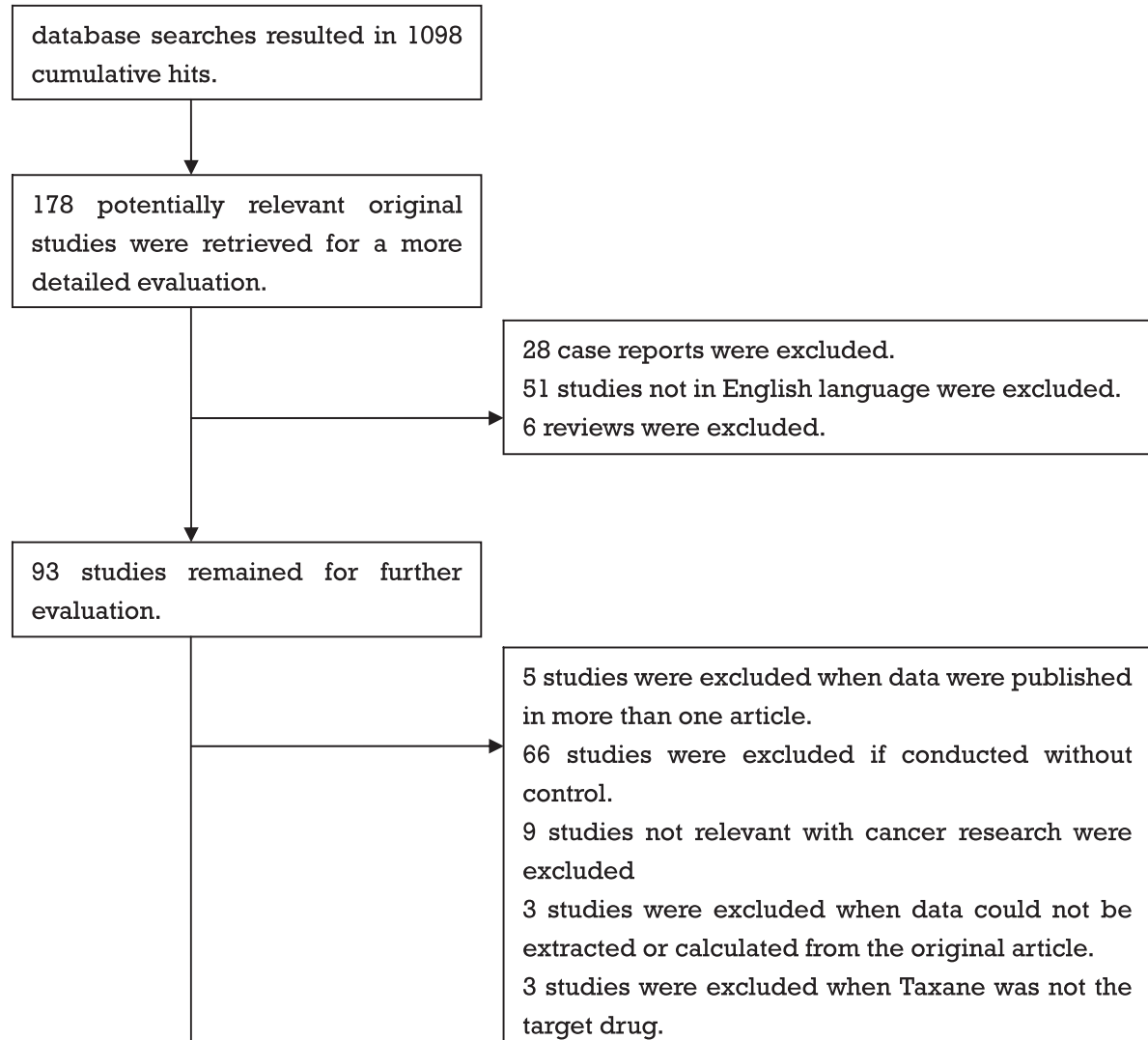

7 studies with useful information meeting the study-criteria were included in this meta-analysis, of which 1 was only published as abstract at the time of the trial search.

5 studies were excluded when data were published in more than one article. control.

9 studies not relevant with cancer research were excluded

3 studies were excluded when data could not be extracted or calculated from the original article. target drug.

Figure 1 Flow-chart for identification of eligible studies. 
were extracted from each study, however some articles did not contain all of the following information: first author, publication year, country of patient's origin, treatment regimen, patient number, age, gender, treatment line, ECOG (Eastern Cooperative Oncology Group) performance status (PS) or WHO status or Karnofsky status (KPS), median overall survival (OS), progression-free survival (PFS), overall response rate (ORR), adverse events (AEs), specific grade 3-4 toxicity data and general symptoms (alopecia, infection, and asthenia), hematological system syndrome (neutropenia, thrombocytopenia, and anemia), digestive system syndrome (nausea/vomiting, diarrhea, and anorexia), and neuropathy. In studies where the log hazard ratio (HR) and its variance was not explicitly presented the method described by Parmar et al. was applied to extract estimates of these statistics (Parmar et al. 1998). In those instances where studies contained overlapping sets of patients, the longest follow-up or the largest number of events was selected. The methodological quality of the reports integrated in this meta-analysis was evaluated using the Jadad composite scale (Jadad et al. 1996; Moher et al. 1998). A general quality score was applied to each study as follows: 0 (non-randomized controlled trials), 1, 2 (low quality studies), 3, 5 (high quality studies).

\section{Statistical analysis}

The outcomes relevant for this meta-analysis were PFS, OS, ORR and toxicity. PFS was defined by the period from random assignment to the first documented disease progression. OS was defined by the period from random assignment to death from any cause, censoring patients who had not died at the date last known alive. ORR was defined as the sum of partial and complete response rates (according to the Response Evaluation Criteria in Solid Tumors (RECIST) (Therasse et al. 2000). Toxicity was graded according to the Common Toxicity Criteria version 2 (http://ctep.cancer.gov). The overall HRs for OS and PFS, the odds ratios (ORs) for ORR and AEs were calculated using statistical software (Stata version 13.0). Efficacy analysis was based on the intent-to-treat population, which was defined as all randomly assigned patients. All patients who received at least one dose of the study drug were included in safety analysis. A p-value less than 0.05 was considered significant. An HR > 1 reflects a favorable outcome in the Tax-PF arm for response rate while an OR > 1 indicates better overall response rates or higher toxicity in the Tax-PF arm. Both the fixed-effects model and the random-effects model was used to calculate the pooled estimates of efficacy. The quantification of the heterogeneity was calculated by the Cochrane $Q$ statistic and the $I^{2}$ value. The assumption of homogeneity was deemed invalid, when a p-value was $<0.1$. Then the random-effects models were used after exploring the causes of heterogeneity. Otherwise, the fixed-effects models were used. The results of this meta-analysis were presented by forest plots. The individual squares represent each study's HR or OR estimate while the lines extending from the squares represent the $95 \%$ confidence interval (CI) for the estimate. The size of the square represents the weight that the corresponding study exerts in the meta-analysis. In addition, the funnel plot, in which the standard error of log (OR) of each study was plotted against its log (OR) and Begg's and the Egger's linear regression test were used to estimate the publication bias. The significance of the intercept was displayed using the $\mathrm{t}$-test suggested by Begg ( $<<0.05$ was considered as statistically significant) (Egger et al. 1997) (see Additional file 1: Figure S1).

\section{Results}

\section{Description of included trials}

A total of 1098 potentially relevant papers or abstracts were initially retrieved from the databases, of which 1091 could be excluded after thorough screening. A flow chart summarizing search results and exclusion strategy is provided in Figure 1. Finally, seven clinical trials were selected for the meta-analysis (Hitt et al. 2005; Posner et al. 2007; Vermorken et al. 2007; Pointreau et al. 2009; Vermorken et al. 2011; Lorch et al. 2011; Hitt et al. 2014).The main characteristics and detailed induction chemotherapy regimens are summarized in Table 1.

\section{Three-year efficacy rate}

Four trials (Posner et al. 2007; Vermorken et al. 2007; Pointreau et al. 2009; Hitt et al. 2014) provided data regarding the 3-year PFS rate. When combined, the data from the four trials yielded an estimated common HR of 1.24 (95\% CI: 1.08 to 1.43). A significantly positive effect on survival was found for the use of Tax-PF for induction chemotherapy $(P=0.002)$. Five trials (Hitt et al. 2005; Posner et al. 2007; Vermorken et al. 2007; Pointreau et al. 2009; Hitt et al. 2014) provided data on the 3-year OR rate. Patients treated with the Tax-PF regimen had a significantly longer 3-year OR rate (HR: 1.14; 95\% CI: 1.03 to $1.25 ; P=0.008$ ). However, a between-trial-heterogeneity was observed for the OS analysis with an $I^{2}$ value of $57.2 \%$ $(P=0.053)$, but not in PFS $(P=0.545)$. This heterogeneity was mainly related to the Spanish Head and Neck Cancer Cooperative Group (TTCC) in 2014 (Hitt et al. 2014). After eliminating this study, a reduction in the hazard of progression for Tax-PF group (HR 1.19, 95\% CI 1.07 to 1.32, heterogeneity $P=0.132, I^{2}=46.5 \%$ ) was found. The main study results are detailed in Figure 2.

\section{Five-year efficacy rate}

Of the four eligible studies, 2 trials (Vermorken et al. 2011; Lorch et al. 2011) were a long-term update to previous trials. From these studies, we could extract data to calculate 
Table 1 Characteristics of randomized controlled clinical trials in the meta-analysis

\begin{tabular}{|c|c|c|c|c|c|c|c|c|c|c|c|c|c|c|c|}
\hline $\begin{array}{l}\text { First } \\
\text { author }\end{array}$ & Year & Study & NCT number & Center & $\begin{array}{l}\text { Inclusion } \\
\text { period }\end{array}$ & $\begin{array}{l}\text { Total } \\
\text { number }\end{array}$ & $\begin{array}{l}\text { TPF/ } \\
\text { PF }\end{array}$ & $\begin{array}{l}\text { Follow-up } \\
\text { mean } \\
\text { (month) }\end{array}$ & $\begin{array}{l}\text { Induction } \\
\text { Chemotherapy (IC) }\end{array}$ & $\begin{array}{l}\text { Treatment } \\
\text { after IC }\end{array}$ & $\begin{array}{l}\text { Performance } \\
\text { status }\end{array}$ & $\begin{array}{l}\text { Median } \\
\text { age(year) }\end{array}$ & $\begin{array}{l}\text { Male } \\
(\%)\end{array}$ & $\begin{array}{l}\text { Unresectable } \\
\text { (\%) }\end{array}$ & $\begin{array}{l}\text { Jaded } \\
\text { score }\end{array}$ \\
\hline Hitt & 2005 & / & / & $\mathrm{SP}$ & $\begin{array}{l}1998- \\
2001\end{array}$ & 382 & $\begin{array}{l}189 / \\
193\end{array}$ & 23.2 & $\begin{array}{l}\text { paclitaxel+PF } \\
\text { vs PF }\end{array}$ & chemoradiotherapy & ECOG 0-1 & $\begin{array}{l}\text { TPF 56/PF } \\
55\end{array}$ & $\begin{array}{l}\text { TPF 94/ } \\
\text { PF } 94\end{array}$ & TPF 64/PF 66 & 4 \\
\hline Hitt & 2014 & TTCC & NCT00261703 & $\mathrm{SP}$ & $\begin{array}{l}2002- \\
2007\end{array}$ & 439 & $\begin{array}{l}155 / \\
156\end{array}$ & 23.8/22.1 & $\begin{array}{l}\text { docetaxel+PF } \\
\text { vs PF }\end{array}$ & chemoradiotherapy & ECOG 0-1 & $\begin{array}{l}\text { TPF 58/PF } \\
58\end{array}$ & $\begin{array}{l}\text { TPF 94/ } \\
\text { PF } 93\end{array}$ & 100 & 4 \\
\hline Lorch & 2011 & TAX324 & NCT00273546 & US & $\begin{array}{l}1999- \\
2003\end{array}$ & 501 & $\begin{array}{l}255 / \\
246\end{array}$ & 72.2 & $\begin{array}{l}\text { docetaxel+PF } \\
\text { vs PF }\end{array}$ & chemoradiotherapy & WHO-PS 0-1 & $\begin{array}{l}\text { TPF 55/PF } \\
56\end{array}$ & $\begin{array}{l}\text { TPF 84/ } \\
\text { PF } 83\end{array}$ & $\begin{array}{l}\text { TPF 67/ } \\
\text { PF } 64\end{array}$ & 4 \\
\hline Posner & 2007 & TAX324 & NCT00273546 & US & $\begin{array}{l}1999- \\
2003\end{array}$ & 501 & $\begin{array}{l}255 / \\
246\end{array}$ & 42 & $\begin{array}{l}\text { docetaxel+PF } \\
\text { vs PF }\end{array}$ & chemoradiotherapy & WHO-PS 0-1 & $\begin{array}{l}\text { TPF 55/PF } \\
56\end{array}$ & $\begin{array}{l}\text { TPF 84/ } \\
\text { PF 83 }\end{array}$ & $\begin{array}{l}\text { TPF 67/ } \\
\text { PF } 64\end{array}$ & 4 \\
\hline Vermorken & 2007 & $\begin{array}{l}\text { EORTC } \\
24971 / \\
\text { TAX323 }\end{array}$ & NCT00003888 & $B L$ & $\begin{array}{l}1999- \\
2002\end{array}$ & 358 & $\begin{array}{l}177 / \\
181\end{array}$ & 32.5 & $\begin{array}{l}\text { docetaxel+PF } \\
\text { vs PF }\end{array}$ & radiotherapy & WHO-PS 0-1 & $\begin{array}{l}\text { TPF 53/PF } \\
53\end{array}$ & $\begin{array}{l}\text { TPF 90/ } \\
\text { PF } 90\end{array}$ & 100 & 4 \\
\hline Vermorken & 2011 & $\begin{array}{l}\text { EORTC } \\
24971 / \\
\text { TAX323 }\end{array}$ & NCT00003888 & $B L$ & / & 308 & $\begin{array}{l}156 / \\
152\end{array}$ & 103.2 & $\begin{array}{l}\text { docetaxel+PF } \\
\text { vs PF }\end{array}$ & radiotherapy & / & / & / & 100 & 3 \\
\hline Pointreau & 2009 & GORTEC & NCT00169182 & FR & $\begin{array}{l}2000- \\
2005\end{array}$ & 213 & $\begin{array}{l}110 / \\
103\end{array}$ & 36 & $\begin{array}{l}\text { docetaxel+PF } \\
\text { vs PF }\end{array}$ & $\begin{array}{l}\text { radiotherapy and/or } \\
\text { chemoradiotherapy }\end{array}$ & $\begin{array}{l}\text { Karnofsky } \\
\text { PS 100-80 }\end{array}$ & $\begin{array}{l}\text { TPF } \\
57 / P F 56\end{array}$ & $\begin{array}{l}\text { TPF 92/ } \\
\text { PF } 94\end{array}$ & / & 4 \\
\hline
\end{tabular}




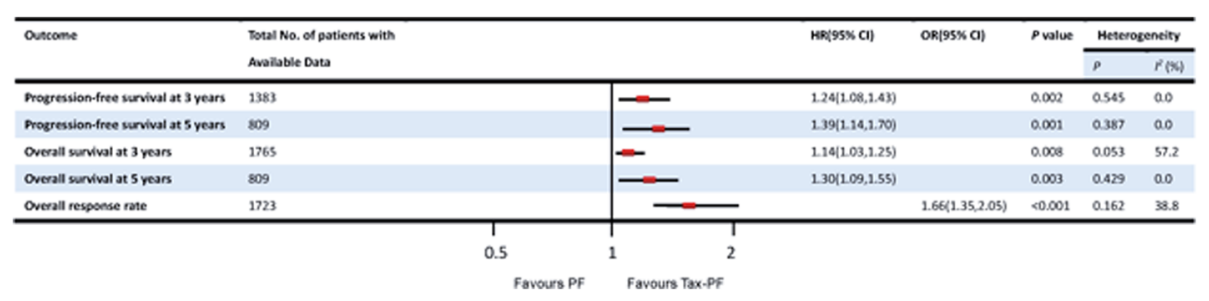

Figure 2 Clinical outcome after three 3 and 5 years.

the five-year efficacy rate for this meta-analysis. Tax-PF induction chemotherapy improved the PFS rate when compared with $\mathrm{PF}$ induction chemotherapy, with an HR of death of 1.39 (95\% CI, 1.14 to $1.70 ; P=0.001$; Figure 2). Tax-PF induction chemotherapy also improved the OS rate, with an HR of 1.30 (95\% CI, 1.09 to $1.55 ; P=0.003)$. The test for heterogeneity of the data yielded a p-value $>0.1$ (PFS: 0.387 and OS: 0.429); thus, we accepted the hypothesis of homogeneity.

\section{Overall response rate}

The data of five trials (Hitt et al. 2005; Posner et al. 2007; Vermorken et al. 2007; Pointreau et al. 2009; Hitt et al. 2014) were included to determine the overall response (WHO criteria) to chemotherapy. Patients treated with Tax-PF had a significantly higher ORR (OR 1.66; 95\% CI, 1.35 to $2.05 ; P<0.001)$. No significant heterogeneity was found among studies used for analysis (heterogeneity $\left.P=0.162, I^{2}=38.8 \%\right)$.

\section{Toxicity}

Data to analyse adverse events could be extracted from seven trials. The results are presented in Figure 3. Patients treated with the Tax-PF regimen had a significantly higher occurrence of grade 3 to 4 febrile neutropenia (OR 2.36; 95\% CI, 1.62 to 3.46; $P<0.001$ ), alopecia (OR 8.22; 95\% CI, 3.99 to $16.92 ; P<0.001$ ), diarrhea (OR 1.57; 95\% CI, 1.05 to $2.36 ; P=0.03$ ) and leukopenia (OR 2.79; 95\% CI, 1.86 to $4.21 ; P<0.001$ ). Heterogeneity was found for some adverse events, which may be attributed to patient characteristics and to the use of different agents at various dosages in the studies.

\section{Publication bias}

Egger's test was performed to determine the publication bias of the literature. The results of Egger's test did not suggest any evidence of publication bias $(P=0.854)$ (see Additional file 1: Figure S1).

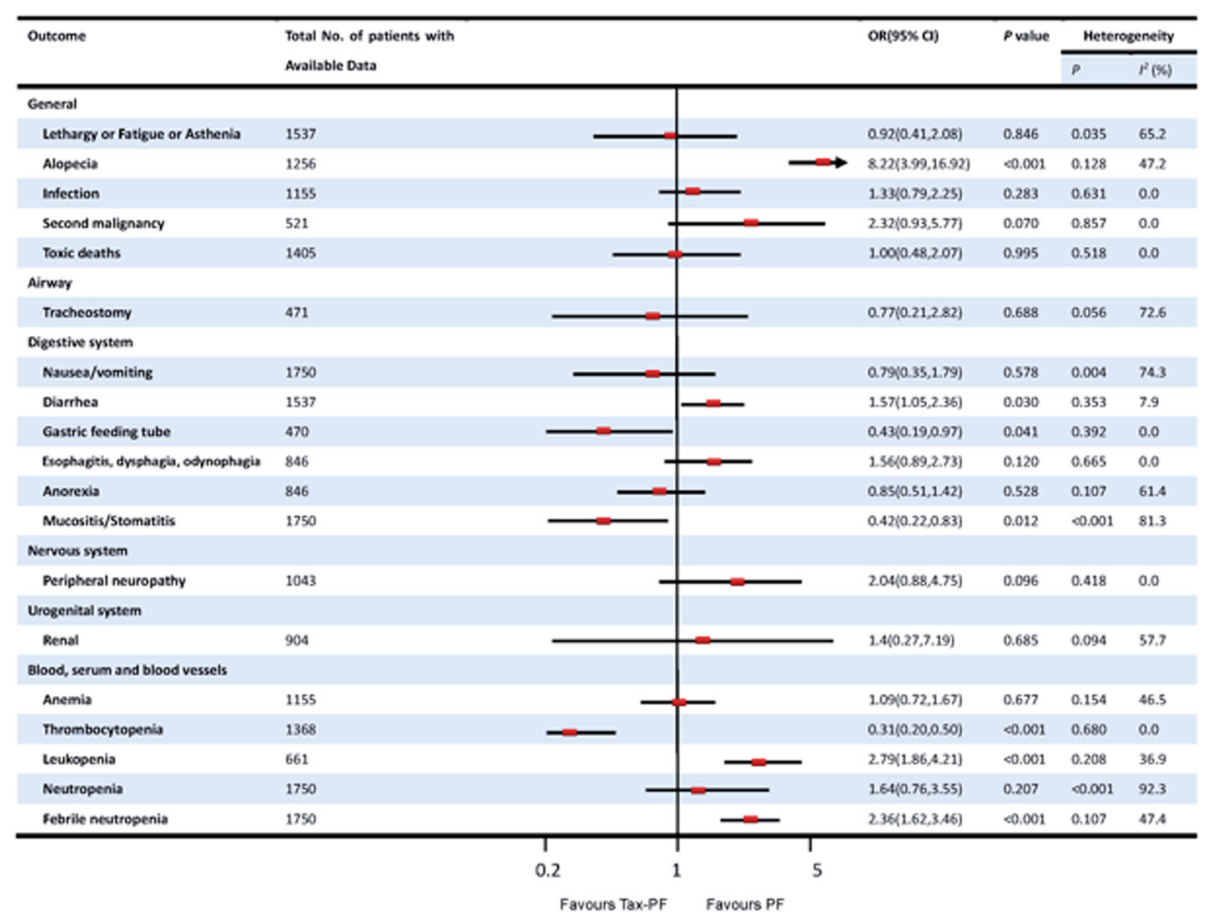

Figure 3 Toxicity profile of Tax-PF and PF regimen. 


\section{Discussion}

Taxanes are a group of anticancer drugs that function by disruption of microtubule assembly and -function and can effectively block the cell cycle in G2/M phase which results in a mitotic arrest (Schrijvers and Vermorken 2000). In vitro studies suggested that taxanes also may play a role in radiation sensitization (Cui et al. 2014). Since the 1990s, taxanes have been evaluated for their potential to treat HNSCC (Qin et al. 2012).

The MACH-NC Collaborative Group performed an individual patient data meta-analysis with an inclusion of 1772 patients that were recruited between 1998 and 2007. Patients treated with Tax-PF had the benefit of a higher rate of loco-regional control (HR, 0.79; 95\% CI, 0.66-0.97; $P=0.007$ ), suffered from distant failures less frequently $(\mathrm{HR}, 0.63 ; 95 \% \mathrm{CI}, 0.45-0.89 ; \mathrm{p}=0.009)$ and showed an absolute decrease in mortality at 5 years of 9.3\% (PF vs TPF: $60.1 \%$ vs $50.8 \%$ ). Nevertheless, the trials displayed heterogeneity regarding criteria such as patient inclusion, patient characteristics, drug regimens, tumor site, treatment intent, primary endpoint, and especially, definitive local treatment (Forastiere et al. 2013). The individual trial results also diminished the importance of the meta-analysis (Mak and Glisson 2014). The outcome of induction chemotherapy with a three-drugcombination consisting Tax-PF for locally advanced head and neck cancer is still a subject of debate and will remain so for the near future.

This meta-analysis evaluated not only the 3-year efficacy and safety, but also demonstrated for the first time a significant improvement in 5-year efficacy and safety of Tax-PF from two clinical studies. The long-term results from the other three trials (Hitt et al. 2014; Hitt et al. 2005; Pointreau et al. 2009) are not available at present. Therefore, we conclude at this point in time that the induction chemotherapy regimen using Tax-PF is superior to the PF regimen in terms of efficacy according to the currently available data. However, the long-term results of the currently ongoing trials should be included whenever available to increase the validity of this statement.

With regards to toxicities, the Tax-PF regimen led to a higher rate of grade 3 to 4 febrile neutropenia, alopecia, diarrhea and leucopenia as it has been shown in this meta-analysis (Figure 3). No difference was seen in toxicity-related mortality, implying that there was no increase in treatment-related deaths with Tax-PF treatment as compared with PF-regimen alone. The incidences of lethargy, infection, nausea and vomiting, peripheral neuropathy, renal function and anemia were not significantly different.

Severe adverse effects seemed predictable and manageable. Taking into account the toxicity-profile of Tax-PFinduction chemotherapy on one hand and the improved PFS and OS on the other future studies should aim to identify characteristics of treated patients that will help to determine the risk and benefit of distinct groups. One currently proposed strategy is a stratification of trial-results based on the distinct etiologies of HNSCC in future research since human papillomavirus (HPV)- and tobaccorelated HNSCC exist (Qian et al. 2014; Qian et al. 2013). Fakhry et al. observed the HPV status of oropharyngeal HNSCC in a prospective clinical trial and confirmed, that tumor HPV status is strongly associated with therapeutic response and survival (Fakhry et al. 2008). Patients with HPV-positive tumors displayed higher response rates to induction chemotherapy including intravenous paclitaxel ( $82 \%$ vs $55 \%, P=0.01$ ) and after chemoradiation treatment ( $84 \%$ vs $57 \%, P=0.007$ ) than those with HPV-negative tumors. After a median follow-up of 39.1 months, compared with patients with HPV-negative tumors, patients with HPV-positive tumors demonstrated a significant improved OS (2-year OS $=95 \%$ vs $62 \%$, difference $=33 \%, 95 \% \mathrm{CI}=18.6 \%$ to $47.4 \%, \mathrm{P}=0.005$, log-rank test). Consequently, de-escalation treatment protocols of HPV-associated HNSCC were developed (Masterson et al. 2014). However, it will be necessary and of clinical interest to identify further the underlying mechanisms that determine a response to induction chemotherapy in patients with HPV-associated HNSCC and non-HPV-associated HNSCC to facilitate a proper selection of patients that are most likely to benefit from this therapy and thereby justifying the relatively high risk of therapy-induced toxicity. These approaches may include reverse bedside-to-bench research to stratify the influence of patient' habits and biological factors on therapeutic outcome.

As stated by Forastiere et al. and others the ideal sequence of chemotherapy, radiation, and surgery for the management of loco-regionally advanced HNSCC has not been finally defined yet (Forastiere et al. 2013; Argiris et al. 2008).

Although non-surgical standard treatment of locally advanced HNSCC is concurrent chemoradio-therapy (Pignon et al. 2009; Petrelli et al. 2014; Masterson et al. 2014), there is emerging evidence, being now further consolidated and explored, that treatment with a threedrug regimen such as Tax-PF followed by surgery and consolidation chemoradio-therapy of patients with recurrent advanced HNSCC improved the response rates and survival (Yang et al. 2014). Other groups also reported that induction chemotherapy tended to improve clinical outcome with manageable toxicity (Won et al. 2014). Also the choice of the chemotherapeutic agent in a noninduction setting is not without controversy. While some authors view platinum-based chemoradio-therapy as the treatment of choice for locally advanced HNSCC (Petrelli et al. 2014; Masterson et al. 2014) and superior to radiotherapy combined with cetuximab, which should 
therefore be reserved for cases where the application of platinum-based agents is contraindicated, others recently argued that an improved OS and reduced toxicity supports the choice of taxane-based regimens in a concurrent setting over platinum non-taxane containing regimen (Behera et al. 2014). However, the findings also indicated that a better standardization of a taxane-based regimen is needed (Behera et al. 2014).

Some shortcomings of this analysis should be taken into account: First, like every meta-analysis, the quality of the results is limited by the quality of the included trials. Second, treatments were involved in a few trials based on the different dosages. Third, only seven RCTs were included and not all articles contained data of OS, PFS, ORR, and some adverse effects. Fourth, although publication bias was not found, the influence of the omission of further ongoing or yet unpublished studies cannot be included at the time of the preparation of this manuscript. However more long-term evidence from randomized studies is needed to further validate the therapeutic efficacy of Tax-PF. Finally, heterogeneity of the data exists in some outcomes in this meta-analysis, for which differences in patient populations, concurrent chemoradio-therapies, lengths of treatment and tumor performance status across the included trials may be responsible.

In conclusion, our data demonstrate that the Tax-PF induction chemotherapy regimens lead to a significant survival advantage at the cost of an increased rate of toxicity-related adverse effects as compared to the PF regimen. Therefore, before administration of Tax-PF induction chemotherapy regimen, followed by radiotherapy or concurrent chemoradio-therapy, a careful selection of patients seems advisable to reduce the incidence and severity of adverse effects. Ideally, these patients should be included in clinical trials to provide more data for future analysis and perspectively for better clinical decision making. For future research, investigators should include markers in their studies that help to distinguish subsets of patients e.g. according to risk-profile and HPV association of the HNSCC to further characterize groups at high risk for adverse effects and those most likely to benefit.

\section{Additional file}

Additional file 1: Figure S1. Publication bias.

\section{Competing interests}

The authors declare that they have no competing interests.

\section{Authors' contribution}

$X Q$ and $C M$ performed the database searches. $X Q, C M$ and $A E A$ analyzed the data. XQ, CM, AEA, AMK and TK prepared the manuscript. All authors read and approved the final manuscript.

\section{Author details}

'Department of Otolaryngology, Head and Neck Surgery, Charité-Universitätsmedizin Berlin, Campus Benjamin Franklin, Hindenburgdamm 30, 12200 Berlin, Germany. ${ }^{2}$ Department of Histology and Embryology, Zhejiang Provincial Key Laboratory of Medical Genetics, Wenzhou medical University, Wenzhou, China. ${ }^{3}$ Department of Otolaryngology, Head and Neck Surgery, University of Ulm, UIm, Germany. ${ }^{4}$ Clinic for Gynecology, Charité-Universitätsmedizin Berlin, Campus Mitte and Benjamin Franklin, Berlin, Germany.

Received: 9 November 2014 Accepted: 17 April 2015

Published online: 01 May 2015

\section{References}

Argiris A, Karamouzis MV, Raben D, Ferris RL (2008) Head and neck cancer. Lancet 371(9625):1695-1709, doi:10.1016/50140-6736(08)60728-X

Behera M, Owonikoko TK, Kim S, Chen Z, Higgins K, Ramalingam SS, Shin DM, Khuri FR, Beitler JJ, Saba NF (2014) Concurrent therapy with taxane versus non-taxane containing regimens in locally advanced squamous cell carcinomas of the head and neck (SCCHN): a systematic review. Oral Oncol 50(9):888-894, doi:10.1016/.joraloncology.2014.06.014

Blanchard P, Bourhis J, Lacas B, Posner MR, Vermorken JB, Hernandez JJ, Bourredjem A, Calais G, Paccagnella A, Hitt R, Pignon JP, Meta-Analysis of Chemotherapy in H, Neck Cancer IPCG (2013) Taxane-cisplatin-fluorouracil as induction chemotherapy in locally advanced head and neck cancers: an individual patient data meta-analysis of the meta-analysis of chemotherapy in head and neck cancer group. J Clin Oncol 31(23):2854-2860, doi:10.1200/JCO.2012.47.7802

Cui FB, Li RT, Liu Q, Wu PY, Hu WJ, Yue GF, Ding H, Yu LX, Qian XP, Liu BR (2014) Enhancement of radiotherapy efficacy by docetaxel-loaded gelatinase-stimuli PEG-Pep-PCL nanoparticles in gastric cancer. Cancer Lett 346(1):53-62, doi:10.1016/j.canlet.2013.12.002

Egger M, Davey Smith G, Schneider M, Minder C (1997) Bias in meta-analysis detected by a simple, graphical test. BMJ 315(7109):629-634

Fakhry C, Westra WH, Li S, Cmelak A, Ridge JA, Pinto H, Forastiere A, Gillison ML (2008) Improved survival of patients with human papillomavirus-positive head and neck squamous cell carcinoma in a prospective clinical trial. J Natl Cancer Inst 100(4):261-269, doi:10.1093/jnci/djn011

Forastiere AA, Adelstein DJ, Manola J (2013) Induction chemotherapy meta-analysis in head and neck cancer: right answer, wrong question. J Clin Oncol 31(23):2844-2846, doi:10.1200/JCO.2013.50.3136

Hitt R, Lopez-Pousa A, Martinez-Trufero J, Escrig V, Carles J, Rizo A, Isla D, Vega ME, Marti JL, Lobo F, Pastor P, Valenti V, Belon J, Sanchez MA, Chaib C, Pallares C, Anton A, Cervantes A, Paz-Ares L, Cortes-Funes H (2005) Phase III study comparing cisplatin plus fluorouracil to paclitaxel, cisplatin, and fluorouracil induction chemotherapy followed by chemoradiotherapy in locally advanced head and neck cancer. J Clin Oncol 23(34):8636-8645, doi:10.1200/JCO.2004.00.1990

Hitt R, Grau JJ, Lopez-Pousa A, Berrocal A, Garcia-Giron C, Irigoyen A, Sastre J, Martinez-Trufero J, Brandariz Castelo JA, Verger E, Cruz-Hernandez JJ, Spanish H, Neck Cancer Cooperative G (2014) A randomized phase III trial comparing induction chemotherapy followed by chemoradiotherapy versus chemoradiotherapy alone as treatment of unresectable head and neck cancer. Ann Oncol 25(1):216-225, doi:10.1093/annonc/mdt461

Jadad AR, Moore RA, Carroll D, Jenkinson C, Reynolds DJ, Gavaghan DJ, McQuay HJ (1996) Assessing the quality of reports of randomized clinical trials: is blinding necessary? Control Clin Trials 17(1):1-12

Lorch JH, Goloubeva O, Haddad RI, Cullen K, Sarlis N, Tishler R, Tan M, Fasciano J, Sammartino DE, Posner MR, Group TAXS (2011) Induction chemotherapy with cisplatin and fluorouracil alone or in combination with docetaxel in locally advanced squamous-cell cancer of the head and neck: long-term results of the TAX 324 randomised phase 3 trial. Lancet Oncol 12(2):153-159, doi:10.1016/S1470-2045(10)70279-5

Mak MP, Glisson BS (2014) Is there still a role for induction chemotherapy in locally advanced head and neck cancer? Curr Opin Oncol 26(3):247-251, doi:10.1097/CCO.0000000000000073

Masterson L, Moualed D, Liu ZW, Howard JE, Dwivedi RC, Tysome JR, Benson R, Sterling JC, Sudhoff H, Jani P, Goon PK (2014) De-escalation treatment protocols for human papillomavirus-associated oropharyngeal squamous cell carcinoma: a systematic review and meta-analysis of current clinical trials. Eur J Cancer 50(15):2636-2648, doi:10.1016/j.ejca.2014.07.001 
Moher D, Pham B, Jones A, Cook DJ, Jadad AR, Moher M, Tugwell P, Klassen TP (1998) Does quality of reports of randomised trials affect estimates of intervention efficacy reported in meta-analyses? Lancet 352(9128):609-613, doi:10.1016/S0140-6736(98)01085-X

Parmar MK, Torri V, Stewart L (1998) Extracting summary statistics to perform meta-analyses of the published literature for survival endpoints. Stat Med 17(24):2815-2834

Petrelli F, Coinu A, Riboldi V, Borgonovo K, Ghilardi M, Cabiddu M, Lonati V, Sarti E, Barni S (2014) Concomitant platinum-based chemotherapy or cetuximab with radiotherapy for locally advanced head and neck cancer: a systematic review and meta-analysis of published studies. Oral Oncol 50(11):1041-1048, doi:10.1016/j.oraloncology.2014.08.005

Pignon JP, le Maitre A, Maillard E, Bourhis J, Group M-NC (2009) Meta-analysis of chemotherapy in head and neck cancer (MACH-NC): an update on 93 randomised trials and 17,346 patients. Radiother Oncol 92(1):4-14, doi:10.1016/j.radonc.2009.04.014

Pointreau Y, Garaud P, Chapet S, Sire C, Tuchais C, Tortochaux J, Faivre S, Guerrif S, Alfonsi M, Calais G (2009) Randomized trial of induction chemotherapy with cisplatin and 5-fluorouracil with or without docetaxel for larynx preservation. J Natl Cancer Inst 101(7):498-506, doi:10.1093/jnci/djp007

Posner MR, Hershock DM, Blajman CR, Mickiewicz E, Winquist E, Gorbounova V, Tjulandin S, Shin DM, Cullen K, Ervin TJ, Murphy BA, Raez LE, Cohen RB, Spaulding M, Tishler RB, Roth B, Viroglio Rdel C, Venkatesan V, Romanov I, Agarwala S, Harter KW, Dugan M, Cmelak A, Markoe AM, Read PW, Steinbrenner L, Colevas AD, Norris CM Jr, Haddad RI, Group TAXS (2007) Cisplatin and fluorouracil alone or with docetaxel in head and neck cancer. N Engl J Med 357(17):1705-1715, doi:10.1056/NEJMoa070956

Qian X, Wagner S, Ma C, Klussmann JP, Hummel M, Kaufmann AM, Albers AE (2013) ALDH1-positive cancer stem-like cells are enriched in nodal metastases of oropharyngeal squamous cell carcinoma independent of HPV status. Oncol Rep 29(5):1777-1784, doi:10.3892/or.2013.2340

Qian X, Wagner S, Ma C, Coordes A, Gekeler J, Klussmann JP, Hummel M, Kaufmann AM, Albers AE (2014) Prognostic significance of ALDH1A1-positive cancer stem cells in patients with locally advanced, metastasized head and neck squamous cell carcinoma. J Cancer Res Clin Oncol 140(7):1151-1158, doi:10.1007/s00432-014-1685-4

Qin H, Luo J, Zhu YP, Xie HL, Yang WQ, Lei WB (2012) Combination of taxanes, cisplatin and fluorouracil as induction chemotherapy for locally advanced head and neck cancer: a meta-analysis. PLoS One 7(12), e51526, doi:10.1371/journal.pone.0051526

Schrijvers D, Vermorken JB (2000) Role of taxoids in head and neck cancer. Oncologist 5(3):199-208

Siegel R, Ma J, Zou Z, Jemal A (2014) Cancer statistics, 2014. CA Cancer J Clin 64(1):9-29, doi:10.3322/caac.21208

Therasse P, Arbuck SG, Eisenhauer EA, Wanders J, Kaplan RS, Rubinstein L, Verweij J, Van Glabbeke M, van Oosterom AT, Christian MC, Gwyther SG (2000) New guidelines to evaluate the response to treatment in solid tumors. European Organization for Research and Treatment of Cancer. National Cancer Institute of the United States J Natl Cancer Inst 92(3):205-216

Tural D, Kilickap S (2014) Is taxane-cisplatin-fluorouracil superior to cisplatin-fluorouracil as induction chemotherapy in outcome in locally advanced head and neck cancers? J Clin Oncol 32(3):259, doi:10.1200/JCO.2013.52.5592

Vermorken JB, Remenar E, van Herpen C, Gorlia T, Mesia R, Degardin M, Stewart JS, Jelic S, Betka J, Preiss JH, van den Weyngaert D, Awada A, Cupissol D, Kienzer HR, Rey A, Desaunois I, Bernier J, Lefebvre JL, Group ETS (2007) Cisplatin, fluorouracil, and docetaxel in unresectable head and neck cancer. N Engl J Med 357(17):1695-1704, doi:10.1056/NEJMoa071028

Vermorken JB, Remenar E, Van Herpen C, Degardin M, Stewart JS, Karra Gurunath R, Fortpied C (2011) Long-term results from EORTC24971/TAX323: comparing TPF to PF in patients with unresectable squamous cell carcinoma of the head and neck (SCCHN). J Clin Oncol 29:5530, abstract

Won HS, Lee YS, Jeon EK, Hong SH, Kang JH, Kim YS, le Yoo R, Sun DI, Kim MS (2014) Clinical outcome of induction chemotherapy in locally advanced head and neck squamous cell carcinoma. Anticancer Res 34(10):5709-5714

Yang WC, Chen CH, Tang JY, Wu CF, Liu YC, Sun Y, Lin SF (2014) Induction chemotherapy with docetaxel, cisplatin and fluorouracil followed by surgery and concurrent chemoradiotherapy improves outcome of recurrent advanced head and neck squamous cell carcinoma. Anticancer Res 34(7):3765-3773

\section{Submit your manuscript to a SpringerOpen ${ }^{\circ}$ journal and benefit from:}

- Convenient online submission

- Rigorous peer review

- Immediate publication on acceptance

- Open access: articles freely available online

- High visibility within the field

- Retaining the copyright to your article

Submit your next manuscript at $>$ springeropen.com 